\title{
ESTUDO MORFOLÓGICO DA ARTICULAÇÃO DO JOELHO DE COELHOS APÓS A REPARAÇÃO DE UM DEFEITO OSTEOCONDRAL ${ }^{1}$
}

\author{
Celso Massaschi Inouye ${ }^{2}$ \\ Djalma José Fagundes ${ }^{3}$ \\ Flávio Faloppa ${ }^{4}$ \\ Neil Ferreira Novo ${ }^{5}$ \\ Yara Juliano ${ }^{6}$ \\ Arthur Silveira de Figueiredo ${ }^{7}$ \\ Murched Omar Taha ${ }^{8}$
}

\begin{abstract}
Inouye CM, Fagundes DJ, Faloppa F, Novo NF, Juliano Y, Figueiredo AS, Taha MO. Estudo morfológico da articulação do joelho de coelhos após a reparação de um defeito osteocondral. Acta Cir Bras [serial online] 2002 Nov-Dez;17(6). Disponível em URL: http://www.scielo.br/acb.

RESUMO - Objetivo: Com a finalidade de estudar a morfologia da articulação do joelho de coelhos após a reparação de um defeito osteocondral padronizado com fio de sutura polidioxanone, procedeuse a criação de um defeito osteocondral em côndilo femoral medial do joelho de 80 coelhos, albinos, machos, com idade entre 5 a 8 meses e peso entre 2.600 e $3.000 \mathrm{~g}$. Métodos: Os animais foram distribuídos em 2 grupos com seguimentos de 7 e 42 dias e submetidos à técnica A (ressecção e retirada do fragmento osteocondral; recolocação e síntese de fio PDX-00), técnica B (ressecção e retirada do fragmento osteocondral; reposição como enxerto autólogo no joelho contralateral, após rotação de $180^{\circ}$ no sentido ântero-posterior; síntese com fio PDX-00) ou técnica C (ressecção e retirada do fragmento osteocondral deixando o defeito padrão vazio, nos joelhos contralaterais aos operados pela técnica A ou B) como controle. Resultados: Fez-se estudo clínico, radiográfico, macroscópico e histológico nos dois grupos mostrando que a recolocação do fragmento ou enxerto autólogo osteocondral facilita a perfeita integração dos fragmentos aos côndilos femorais, sem deslocamento ou necrose cartilaginosa ou óssea; que nos joelhos submetidos a ressecção simples do fragmento com seguimento de 42 dias, não houve formação de cartilagem na superfície articular, havendo predisposição à formação de osteofitos, mostrando relação significante entre a técnica $\mathrm{C} e$ a presença de osteofitos. Conclusão: Concluiu-se que a reconstituição da superfície articular com recolocação do fragmento ou o enxerto autólogo osteocondral fixado com fio de sutura PDX é exeqüível e apresentou melhor resultado do que a ressecção simples do fragmento.
\end{abstract}

DESCRITORES - Polidioxanone. Fratura osteocondral. Coelho.

1. Resumo de Tese de Doutorado - Área de Técnica Operatória e Cirurgia Experimental - Universidade Federal de São Paulo Escola Paulista de Medicina - UNIFESP-EPM.

2. Professor Titular do Departamento de Clínica Cirúrgica da Universidade Federal de Mato Grosso do Sul - UFMS.

3. Coordenador do Programa de Pós-graduação em Técnica Operatória e Cirurgia Experimental da UNIFESP-EPM.

4. Professor Associado da Disciplina de Cirurgia de Mão da UNIFESP-EPM.

5. Professor Titular da Disciplina de Bioestatística da UNIFESP-EPM.

6. Professor Adjunto da Disciplina de Bioestatística da UNIFESP-EPM.

7. Professor Titular da Disciplina de Ortopedia e Traumatologia da UFMS.

8. Professor Adjunto da Disciplina de Técnica Operatória e Cirurgia Experimental da UNIFESP-EPM. 


\section{INTRODUÇÃO}

A reparação de lesões da cartilagem articular com perda de substância, representa um problema cuja solução satisfatória ainda não foi encontrada. A cicatrização destas lesões ocorre com substituição da cartilagem por tecido fibroso ou fibrocartilagem ${ }^{1,2}$.

As lesões que comprometem o osso subcondral têm o crescimento de tecido de granulação tão ativo e exuberante, e ocorre tão rapidamente, que dificulta a proliferação do tecido osteocartilaginoso ${ }^{3,4,5,6,7}$. A capacidade reparadora da cartilagem articular é muito limitada, quando é lesada, ocorre aumento da atividade celular, somente nas bordas da mesma, entretanto insuficiente para produzir um processo de reparação do defeito ${ }^{8}$.

Grandes defeitos osteocondrais têm menor potencial de cicatrização que os pequenos defeitos osteocondrais ${ }^{9,10,11}$. A dificuldade para fixação de pequenos fragmentos articulares ocorre pela inexistência de material de pequenas dimensões e resistência suficiente para estabilização. Dentre as técnicas para esta fixação, o material mais utilizado é o fio de Kirschner, com o menor diâmetro de 0,6 milímetros (mm) e comprimento de $200 \mathrm{~mm}$, permitindo uma boa fixação dos fragmentos, desde que exista osso subcondral suficiente para ser impactado e o fio fique embutido. A fixação interna metálica é método universalmente reconhecido, mas sua remoção é necessária ${ }^{12}$.

Parafusos de microfragmentos, com $4 \mathrm{~mm}$ de diâmetro e $18 \mathrm{~mm}$ de comprimento, facilitam a estabilização do fragmento, porém se faz necessário que tenha osso subcondral suficiente para manter a cabeça embutida dentro da cartilagem para não permanecer saliente na superfície articular. A fixação interna metálica é um método universalmente reconhecido, mas sua remoção é freqüentemente necessária ${ }^{12}$.

Diversos autores investigaram alternativas a estes métodos de fixação: adesivos de cianocrilato ${ }^{13,14}$, cimento de polimetilmetacrilato ${ }^{15,16}$ e cola de fibrina $^{12,15,17,18,19}$.

Nas lesões osteocondrais com perda de substância existe a necessidade do uso de tecido biológico autógeno, que seja capaz de produzir cartilagem quando transplantado para um defeito da superfície $\operatorname{articular}^{11,20,21}$.

Os enxertos osteoarticulares são, teoricamente, alternativas atraentes porque os enxertos de cartilagem hialina restabelecem a superfície articular normal e são relativamente resistentes a rejeição imunológica ${ }^{22}$.
A dificuldade em encontrar material inócuo, que cause pouco ou nenhuma interferência no processo de reparação da lesão articular, originou a proposta deste trabalho: a utilização de fio de sutura monofilamentado, absorvível, polidioxanone (PDX), de uso difundido em outros tecidos, custo relativamente baixo; fácil manuseio; completamente absorvido pelos tecidos, e sua degradação ocorre através de um processo de hidrólise e menos por ação enzimática não específica, não se acumulando em nenhum tecido corporal, sendo o material absorvido eliminação pela respiração, urina e fezes ${ }^{23}$.

Na revisão da literatura não se encontrou nenhum trabalho que avaliasse a fixação de fragmentos osteocondrais articulares com fio de sutura, quer sejam esses fragmentos originais da lesão ou enxertos autólogos. Assim julgou-se pertinente a proposta do estudo experimental de fixação, com fio PDX, de fragmentos osteocondrais articulares originados de lesão provocada ou de um fragmento autólogo em côndilos femorais de coelhos.

\section{MÉTODOS}

\section{Amostra}

Oitenta coelhos albinos, machos, Nova Zelândia, 5 a 8 meses de idade, peso entre 2600 e $3000 \mathrm{~g}$, foram distribuídos, por sorteio, em dois grupos, com quarenta animais cada um: Grupos I e II, com seguimentos de 7 e de 42 dias, respectivamente. Cada grupo foi subdividido em dois subgrupos: Subgrupo A (oitenta joelhos, submetidos a procedimento operatório pela técnica A ou técnica C, alternadamente); Subgrupo B (oitenta joelhos, submetidos a procedimento operatório pela técnica $\mathrm{B}$ ou técnica $\mathrm{C}$, alternadamente).

\section{Procedimentos}

Os coelhos foram privados de ração seis horas antes do ato operatório e receberam como medicação pré-anestésica $0,1 \mathrm{~mL} . \mathrm{Kg}^{-1}$ de acepromazina, na concentração de $10 \mathrm{mg} \cdot \mathrm{mL}^{-1}$, por via intramuscular. Quinze minutos após, receberam como medicação anestésica $10 \mathrm{mg} . \mathrm{Kg}^{-1}$ de xilazina na concentração de $20 \mathrm{mg} \cdot \mathrm{mL}^{-1}$ e $25 \mathrm{mg} \cdot \mathrm{Kg}^{-1}$ de quetamina na concentração de $50 \mathrm{mg} \cdot \mathrm{mL}^{-1}$, pela mesma via da medicação préanestésica.

Para a mensuração radiográfica do ângulo de extensão dos joelhos em posicionamento látero-lateral, os animais foram colocados em decúbito supino em artefato composto de dois blocos de isopor em formato de paralelepípedo: bloco A medindo $250 \mathrm{~mm}$ de comprimento x $200 \mathrm{~mm}$ de altura x $200 \mathrm{~mm}$ de largura; 
bloco B medindo $600 \mathrm{~mm}$ de comprimento $\mathrm{x} 200 \mathrm{~mm}$ de altura $\times 200 \mathrm{~mm}$ de largura. Na face superior do bloco A confeccionou-se duas canaletas medindo $80 \mathrm{~mm}$ de comprimento $\times 50 \mathrm{~mm}$ de altura $\times 25 \mathrm{~mm}$ d largura, eqüidistantes $50 \mathrm{~mm}$ de cada aresta do paralelepípedo, comunicando-se com a face anterior. No bloco B, confeccionou-se uma canaleta central da face superior até a face anterior, medindo $450 \mathrm{~mm}$ de comprimento $\mathrm{x}$ $80 \mathrm{~mm}$ de altura $\times 100 \mathrm{~mm}$ de largura, e duas canaletas laterais medindo $150 \mathrm{~mm}$ de comprimento $\mathrm{x} 100 \mathrm{~mm}$ de altura $\mathrm{x} 15 \mathrm{~mm}$ de largura, para acomodação do chassis que contém o filme radiográfico.

Nos joelhos foi afixado um pêndulo metálico padronizado em $1 / 8$ do peso corporal dos animais, para exercer força de tração, mantendo os joelhos em extensão. A padronização do peso seguiu as normas da Ortopedia e Traumatologia para tração contínua músculo-esquelética nas fraturas de membros inferiores em humanos ${ }^{24}$.

Com os coelhos instalados na mesa operatória em decúbito dorsal, com rotação cervical lateral para manter livre as vias aéreas, as regiões anterior, lateral e medial dos joelhos foram epiladas e lavadas com iodopirrolidina tópico e solução salina. Foi feita anti-sepsia com solução de álcool iodado $2 \%$ em ambos membros posteriores e a colocação dos panos esterilizados fenestrados, isolando-se os joelhos. Após tração digital da pele no sentido ântero-lateral com objetivo de prevenir o contato da cicatriz operatória com o solo e as gaiolas, fez-se incisão da pele e tecido celular subcutânea com $30 \mathrm{~mm}$ de comprimento, em posicionamento parapatelar lateral, iniciando-se a $10 \mathrm{~mm}$ proximal do polo superior da patela até o nível da epífise proximal da tíbia, mantendo $10 \mathrm{~mm}$ de distância da borda lateral da patela.

Após afastamento mecânico da pele e tela subcutânea, foi feita uma incisão de $30 \mathrm{~mm}$ de comprimento na cápsula articular lateral, no sentido longitudinal; luxação lateral da patela e do aparelho muscular extensor para exposição do côndilo femoral medial; flexão do joelho a noventa graus, mantendo-se a patela luxada lateralmente; identificação da origem do ligamento cruzado posterior, tomando-a como nível da osteotomia no plano crânio-caudal no côndilo femoral medial para a criação de um defeito padrão com $5 \mathrm{~mm}$ de comprimento x $3 \mathrm{~mm}$ de largura x $2 \mathrm{~mm}$ de profundidade na borda ântero-interna do côndilo femoral medial.

Com paquímetro, mediu-se a distância do centro do defeito padrão até o ápice da fossa supracondiliana posterior do côndilo femoral medial.

Com broca número 2, em "chama de vela", com $20 \mathrm{~mm}$ de comprimento e $0,5 \mathrm{~mm}$ de diâmetro, adaptada a um perfurador elétrico de rotação controlada, perfurou-se dois orifícios eqüidistantes entre si em $3 \mathrm{~mm}$, afastados $1 \mathrm{~mm}$ das bordas do maior comprimento do defeito padrão, transfixando-se o fragmento osteocondral resultante da osteotomia. Com uma broca medindo $40 \mathrm{~mm}$ de comprimento e $1 \mathrm{~mm}$ de diâmetro realizou-se dois orifícios paralelos no côndilo femoral medial, partindo do defeito padrão, a $1 \mathrm{~mm}$ das bordas de maior comprimento, em direção à face lateral do côndilo lateral.

Pela técnica A, o fragmento osteocondral foi recolocado em seu leito original, transfixado e fixado por laçada em "U" com fio PDX 00, preso por quatro nós na face lateral do côndilo femoral lateral; pela técnica $\mathrm{B}$, o fragmento foi usado como enxerto autólogo osteocondral no joelho oposto, sendo fixado de modo similar à técnica $\mathrm{A}$, após sua rotação em 180 graus, no sentido ântero-posterior no côndilo femoral medial; e como procedimento-controle (técnica $\mathrm{C}$ ), o fragmento osteocondral foi simplesmente retirado mantendo-se o defeito padrão vazio.

Fechamento da cápsula articular com pontos simples, separados de fio PDX 00; da tela subcutânea e da pele, em plano único, com sutura contínua de fio de poliamida monofilamentar 5.0; deixando-se as feridas operatórias descobertas e os membros operados sem nenhum tipo de imobilização externa, com a finalidade de observar o comportamento da síntese; o uso de antibiótico profilático foi dispensado.

Para a recuperação anestésica, os coelhos foram devolvidos às suas gaiolas, permanecendo envoltos pelos panos operatórios para evitar perda de calor corporal. Foi permitido aos coelhos reação e água à vontade e apoio imediato dos membros operados.

Os coelhos dos Grupos I e II foram submetidos a exame radiográfico para mensuração do ângulo de extensão dos joelhos ou ângulo fêmuro-tibial em extensão dos joelhos, no pré e pós-operatório, com 7 e 42 dias, respectivamente.

Para padronização das linhas que dão origem ao ângulo fêmuro-tibial, utilizou-se os seguintes parâmetros: a) mensuração realizada em posicionamento láterolateral; b) identificação do ápice da fossa supracondiliana posterior do fêmur; c) traçado de uma linha perpendicular à cortical anterior do fêmur com marcação de seu ponto médio; d) traçado de uma segunda linha paralela à primeira, em posição proximal $30 \mathrm{~mm}$, com marcação de seu ponto médio; e) traçado de uma linha longitudinal unindo ambos pontos médios previamente assinalados, considerada a linha longitudinal do fêmur; f) traçado de uma linha perpendicular à cortical posterior da tíbia com marcação de seu ponto médio; g) traçado de uma segunda linha paralela à primeira, em posição proximal $30 \mathrm{~mm}$, com marcação de seu ponto médio; h) traçado de uma linha longitudinal por ambos pontos médios previamente assinalados, considerada a linha 
longitudinal da tíbia; i) a intersecção das linhas longitudinais femoral e tibial forma o ângulo de extensão do joelho a ser mensurado.

Após eutanásia com injeção pentobarbital sódico, na dose de $60 \mathrm{mg} . \mathrm{Kg}^{-1}$, por via intramuscular, os membros posteriores foram desarticulados no quadril e os fêmures dissecados. Com um paquímetro, mediuse a distância entre o centro da região operatória e o ápice da fossa supracondiliana posterior do côndilo femoral medial, com finalidade de observar o crescimento de tecido de reparação no defeito padrão, na técnica $\mathrm{C}$, ou eventual desvio ou necrose do fragmento, nas técnicas A e B.

As peças femorais de ambos lados, foram fixadas em formalina $10 \%$ e enviadas à Disciplina de Anatomia Patológica da Universidade Federal de Mato Grosso do Sul para processamento histológico. As lâminas obtidas foram coradas com Hematoxilina e Eosina (HE) e pelo Tricrômico de Gomory e submetidas a análise microscópica.

\section{Análise estatística}

Para análise estatística dos resultados foram aplicados os seguintes testes: quiquadrado, MannWhitney, Wilcoxon e " $t$ " de Student, e em todos eles fixou-se em 0,05 ou 5\% o nível de rejeição da hipótese de nulidade.

\section{RESULTADOS}

Quanto ao peso, observou-se que no Grupo I, os animais perderam peso $(t=13,86)$, e no grupo II, houve ganho ponderal $(\mathrm{t}=4,69)$.

Os ângulos de extensão no pós-operatório de 7 e de 42 dias apresentaram-se sempre menores do que os ângulos de extensão no pré-operatório $(\mathrm{Z}=3,23)$, e no pós-operatório de 7 dias, o ângulo foi ainda menor do que no pós-operatório de 42 dias $\left(c^{2}=23,32\right)$ (Figuras 1 e 2 ).

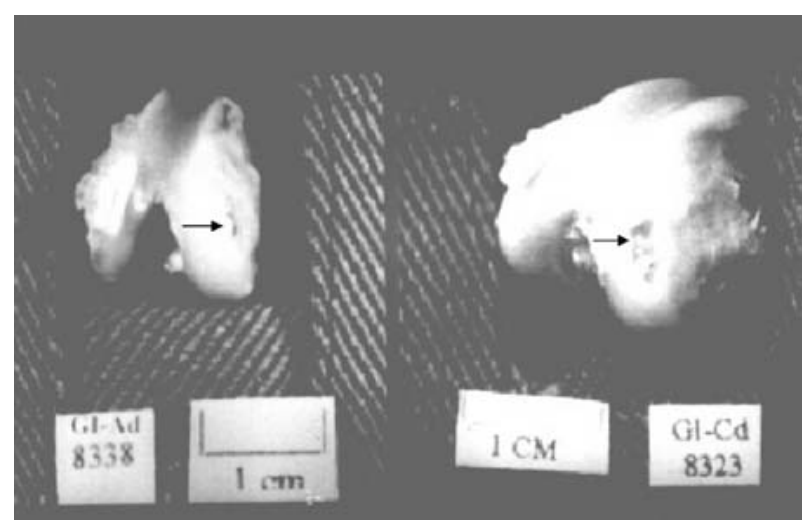

FIGURA 1 - Fotografia A: Pós-operatório de 7 dias; técnica A: síntese do fragmento com fio PDX (seta); joelho direito. Fotografia B: Pós-operatório de 7 dias; técnica C: ressecção do fragmento (seta); joelho direito.

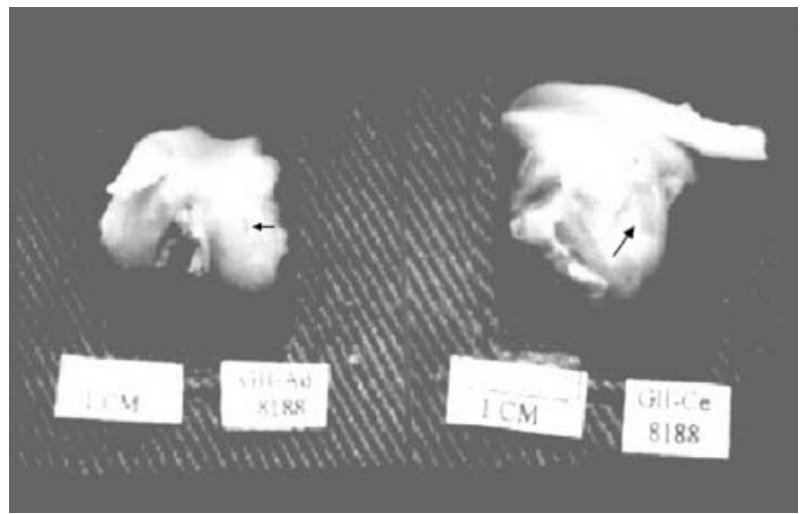

FIGURA 2 - Fotografia A: Pós-operatório de 42 dias; técnica A: síntese do fragmento com fio PDX (seta); joelho direito Fotografia B: Pós-operatório de 42 dias; técnica C: ressecção do fragmento (seta); joelho esquerdo.

$\mathrm{Na}$ análise macroscópica observou-se a presença de formação de osteofitos nos joelhos operados pela técnica C; no grupo I, se fizeram presentes em 23 dos 40 joelhos operados, enquanto nos joelhos operados pela técnica A se fizeram presentes em 1 joelho; e pela técnica B nenhum osteofito foi observado nos joelhos operados, o que não deu significância estatística. $\mathrm{Na}$ comparação entre as técnicas A e B com o controle $\mathrm{C}$, houve diferença significante $\left(\mathrm{c}^{2}=13,79\right.$ e $\mathrm{c}^{2}=15,17$, respectivamente). No grupo II, todos os joelhos operados com a técnica $\mathrm{C}$ apresentavam osteofitos que de tamanho de $5 \mathrm{~mm}$ a $10 \mathrm{~mm}$ em seus maiores diâmetros, e nos joelhos operados com técnica A ou B, somente 2 apresentavam osteofitos, sendo que na comparação entre as duas últimas técnicas não houve diferença estatisticamente significante; porém, quando comparadas as técnicas $\mathrm{A}$ e $\mathrm{B}$ com a técnica $\mathrm{C}$ houve diferença significante $\left(c^{2}=36,19\right)$.

Observou-se a fixação dos fragmentos osteocondrais e/ou enxerto autólogo submetidos a síntese no leito do defeito padrão em todos os casos da experiência, com exceção de um caso no grupo I: neste caso ocorreu fratura do enxerto com desvio do fragmento e durante a manipulação da peça para colocação em formol, houve desprendimento do fragmento.

$\mathrm{O}$ fio de sutura PDX foi observado nas superfícies articulares de 39 dos 40 joelhos do Grupo I e não foi observado em nenhum joelho no Grupo II, operados pela técnica A ou B.

Na mensuração da distância do centro do defeito padrão, observou-se que os joelhos operados com a técnica $\mathrm{A}$ ou técnica $\mathrm{B}$, não mostraram diferenças entre si, porém, quando comparados com os joelhos operados pela técnica $C$, houve diferença significante $(Z=4,30$ e $\mathrm{Z}=4,31$, respectivamente).

Microscopicamente não houve degeneração da superfície articular dos fragmentos osteocondrais 
recolocados e/ou enxerto osteocondral autólogo. No grupo I as cartilagens permaneceram íntegras, sem necrose, alteração de cor ou qualidade da superfície articular, semelhante à cartilagem do resto da articulação, porém com presença de osteofito.

Os orifícios e a solução de continuidade operatória do defeito padrão, foram preenchidos por tecido cicatricial que apresentou aderência na interface cartilagem/cartilagem e cartilagem/osso subcondral imaturo, com exceção de um caso em que houve fratura e desprendimento do fragmento do enxerto autólogo, com rotura do fio de sutura no grupo I.

Em 39 joelhos operados ainda permaneceram os fios de sutura PDX 00, nas superfícies articulares e nos locais de passagem pela superfície articular; no osso subcondral estavam circundados por tecido inflamatório discreto, tipo reação de corpo estranho.

Nos joelhos submetidos à técnica $\mathrm{C}$ permaneceu aproximadamente $75 \%$ da cavidade do defeito padrão; na sua base havia tecido ósseo imaturo, revestido por uma fina camada de tecido de granulação e início da formação de osteofitos em 23 joelhos (57,5\%).

No grupo II houve completa integridade nas superfícies articulares das três técnicas $\mathrm{A}, \mathrm{B}$ e $\mathrm{C}$, porém com diferenças importantes nos tipos de tecido das superfícies articulares. Nas operações das técnicas A e B houve completo desaparecimento dos fios de sutura PDX 00, as superfícies articulares estavam lisas, cartilagem íntegra, sem alteração de cor, semelhante ao resto da articulação, sem necrose e com presença de osteofitos anteriores ao local das operações em dois joelhos. Os orifícios e a solução de continuidade do defeito padrão estavam preenchidos por tecido fibroso, sem depressão e aderente na interface cartilagem/ cartilagem e cartilagem/osso subcondral maduro, havendo perfeita integração osteocartilaginosa articular.

Nos joelhos operados pela técnica $C$ também houve regularidade da superfície articular, porém sem cartilagem de revestimento; a cavidade estava preenchida com tecido ósseo maduro e revestimento da superfície de contato por tecido fibroso, com espessura discretamente maior do que a superfície articular. Entretanto, na porção anterior ao local do defeito padrão, houve formação de osteofitos que variaram de 5 a $10 \mathrm{~mm}$ nos seus maiores diâmetros.

Nos animais submetidos à técnica $\mathrm{C}$ não houve formação de cartilagem, nem de fibrocartilagem, na superfície articular. Entretanto, nos animais submetidos à técnica $\mathrm{A}$ ou $\mathrm{B}$, houve integração do fragmento com regularidade da superfície articular.

\section{DISCUSSÃO}

No exercício profissional da especialidade de Ortopedia e Traumatologia e Cirurgia de Mão, as lesões osteocondrais agudas ou crônicas são muito freqüentes e o seu reparo continua sendo problema sem solução adequada. Apesar das numerosas observações realizadas durante anos, ainda permanece alguma controvérsia sobre a natureza da resposta da cartilagem articular ao trauma ${ }^{25}$.

As células da cartilagem articular têm capacidade de proliferar sob condições normais e reparar a área danificada, entretanto a maneira como isso ocorre ainda é assunto controverso. O conceito aceito é que a cartilagem articular é tecido estático, não reativo e que, qualquer reparo é realizado pela formação de tecido fibroso não específico ${ }^{4}$.

Dada a dificuldade de dispor-se de material inócuo, capaz de fixar minifragmentos osteocondrais ou osteocondrites dissecantes, em zona de apoio na superfície articular, surgiu a idéia da utilização de fio monofilamentado absorvível para fixar as fraturas de minifragmentos com pontos simples na forma de "U". O fio PDX 00 foi escolhido por ser largamente utilizado em suturas de outros tecidos, de custo relativamente baixo e tecnicamente de fácil manuseio, além de ser completamente absorvido pelo processo de degradação que ocorre principalmente através do processo de hidrólise, não se acumulando nos tecidos corporais ${ }^{23}$.

O fio de PDX, segundo Bourne e col. ${ }^{26}$, dentre os fios absorvíveis é o mais apropriado para casos que requerem até seis semanas para a cicatrização ocorrer; sua dureza e resistência à tração só são inferiores ao poliéster ${ }^{27}$.

O defeito osteocondral na superfície da cartilagem articular, foi padronizado em zona de apoio, com dimensões $5 \times 3 \times 2 \mathrm{~mm}$, pela mesma técnica, instrumental, posição anatômica e cirurgião, após sorteio aleatório dos animais em cada grupo. Difere-se de trabalho onde o defeito osteocondral não obedece a um padrão ${ }^{12}$. Foi escolhido o côndilo medial do joelho por ser anatomicamente de fácil acesso. No côndilo lateral há a origem do tendão extensor do hálux, o que dificulta $o$ acesso operatório.

A fixação dos fragmentos após reconstituição da articulação com ou sem enxerto osteocondral, como descrito por Lane e col. ${ }^{22}$, mostrou que quando adequadamente fixados, os enxertos permanecem viáveis, funcional e estruturalmente intactos durante os 12 meses da experiência; o osso subcondral regenera rapidamente, em período inferior a seis semanas, sem perda de sua função. 
Inouye, $\mathrm{CM}$ et al.

Foi utilizado o enxerto osteocondral como alternativa anatômica e fisiológica, para restituição da superfície articular e por não induzirem rejeição imunológica $^{22}$, onde uma concha delgada de osso subcondral promove estabilidade estrutural para a cartilagem de cobertura, que é suficientemente delgada para ser regenerada rapidamente, sem perda da integridade arquitetônica.

Fazendo uma reflexão sobre o conjunto dos resultados obtidos no experimento comprovou-se que o fio absorvível PDX 00 apresenta resistência ao atrito da superfície e à presença do líquido sinovial, mantendo anatomicamente reduzidos e fixos os fragmentos osteocondrais e/ou enxertos autólogos até a consolidação óssea.

Verificou-se que a recolocação dos fragmentos osteocondrais e/ou enxertos autólogos é amplamente superior no aspecto morfológico da reconstituição articular, quando comparada com a retirada simples do fragmento osteocondral.

Apesar do uso do fio de sutura PDX 00 no ser humano ser de longa data, sua utilização na articulações de coelhos com finalidade de fixar fragmentos osteocondrais foi inédita. Cabe continuar a linha de pesquisa experimental, em outros animais de maior porte e em outras articulações, antes de aplicar-se estes conhecimentos em lesões articulares no ser humano.

\section{CONCLUSÃO}

A reconstituição morfológica do defeito padronizado na superfície articular de joelho de coelhos, com a recolocação de fragmento ou enxerto osteocondral, fixados com fio de sutura monofilamentado absorvível (PDX) é exeqüível e apresenta melhor resultado do que a ressecção simples do fragmento.

\section{REFERÊNCIAS}

1. Clark ER, Clark EL. Microscopic observation on new formation of cartilage and bone in the living mammal. Am J Anat 1942; 70:167-200.

2. Campbell CJ. The healing of cartilage defects. Clin Orthop Rel Res 1969; 64:45-63.

3. Shands AR. The regeneration of hyaline cartilage in joints: an experimental study. Arch Surg 1931; 22:137-78.

4. Calandruccio RA, Gilmer Jr WS. Proliferation, regeneration, and repair of articular cartilage of immature animals. J Bone Joint Surg 1962;44:431-55.

5. Mankin HJ - The reaction of articular cartilage to injury and osteoarthritis. N Engl J Med 1974; 12:1285-91.

6. Mitchell N, Shepard N. The resurfacing of adult rabbit articular cartilage by multiple perforations through the subcondral bone. J Bone Joint Surg 1976; 58:230-3.
7. Radin EL, Rose RM. Role of subchondral bone in the initiation and progression of cartilage damage. Clin Orthop. Rel Res 1986; 213:34-40.

8. Bennett GA, Bauer W, Maddock SJ. A study of the repair of articular cartilage and the reaction of normal joints of adults dogs to surgically created defects of articular cartilage, "joint mice" and patellar displacement. Am J Pathol 1932; 8:499.

9. Kennedy JC, Grainger RW, McGraw RW. Osteochondral fractures of the femoral condyles. J Bone Joint Surg 1966; 48:436-40

10. Aichroth P. Osteochondral fractures and their relationship to osteochondritis dissecans of the knee: an experimental study in animals. J Bone Joint Surg 1971a; 53:448-54.

11. Newman AP. Articular cartilage repair. Am J Sport Med 1998; 26:309-24.

12. Plaga BR, Royster RM, Donigian AM, Wright GB, Caskey PM. Fixation of osteochondral fractures in rabbit knees. J Bone Joint Surg 1992; 74(B):292-6.

13. Harper MC, Ralston M. Isobutyl 2-cyanoacrylate as an osseous adhesive in the repair of osteochondral fractures. J Biomed Mater Res 1983;17:167-77.

14. Harper MC. Stabilization of osteochondral fragments using limited placement of cyanoacrylate in rabbits. Clin Orthop 1988; 231:272-6.

15. Weber SC, Chapman MW. Adhesives in orthopaedic surgery: a review of the literature and in vitro bonding strengths of bonebonding agents. Clin Orthop 1984; 191:249-61.

16. Rutherford CS, Cardea JA, Jesse SD. Polymethylmethacrylate fixation of osteochondral fragments in dog knees. Clin Orthop 1987; 223:287-95

17. Meyers MH, Herron MA. A fibrin adhesive seal for the repair of osteochondral fracture fragments. Clin Orthop 1984; 182:258-63.

18. Keller J, Andreassen TT, Joyce F. Fixation of osteochondral fractures. Acta Orthop Scand 1985; 56:323-6.

19. Schlag G, Redl H. Fibrin sealant in orthopaedic surgery. Clin Orthop 1988; 227:269-85.

20. Engkvist O, Skoog V, Pastacaldi P, Yormuk E, Juhlin R. The cartilaginous potential of the perichondrium in rabbit ear and rib. Scand J Plast Reconstr Surg 1979; 13:275-80.

21. O'Driscoll SW, Salter RB. The repair of major osteochondral defects in joint surfaces by neochondrogenesis with autogenous osteoperiosteal grafts stimulates by continuos passive motion. Clin Orthop Rel Res 1986; 208:131-40.

22. Lane JM, Brighton CT, Ottens HR, Lipton M. Joint resurfacing in the rabbit using an autologous osteochondral graft. J Bone Joint Surg 1977; 59-A:218-22.

23. Böstman OM. Absorbable implants for the fixation of fractures. J Bone Joint Surg 1991; 73:148-53.

24. Vertiz JRR. Elementos de Traumatologia y Ortopedia, 3ed. Buenos Aires: Ediciones Cientificas; 1974.

25. Mankin HJ. The response of articular cartilage to mechanical injury. J Bone Joint Surg 1982; 64:460-6.

26. Bourne RB, Bitar FH, Andreae PR, Martin LM, Finlay JB, Marquis F. In-vivo comparison of four absorbable sutures: Vicryl, Dexon plus, Maxon and PDS. Can J Surg 1988; 31:43-5.

27. Greenwald D, Shumway S, Albear P, Gottlieb L. Mechanical comparison of 10 suture materials before and after in vivo incubation. J Surg Res 1994; 56:372-7. 
Inouye CM, Fagundes DJ, Faloppa F, Novo NF, Juliano Y, Figueiredo AS, Taha MO. Morfologic study of rabbits knee articulation after a reparation of an osteochondral $\phi$ s defect. Acta Cir Bras [serial online] 2002 Nov-Dec;17(6). Available from URL: http://www.scielo.br/acb.

ABSTRACT: Objective: To study the morphology in the rabbit's knee joint after the reparation of a defect in the osteochondral's standardized with suture wire polidioxanone, proceeded a criation of one osteochondral's defect in the medial condyle femoral in 80 rabbit's knees, albinos, males, aged between 5 and 8 months and weight between 2600 and 3000g. Methods: The animals were distributed into 2 groups with following by 7 and 42 days and submitted to the technique A (resection and withdrawal of osteochondral's fragment in the medial condyle femoral and replacement with suture wire monofilament absorbable polidioxanone - PDX), technique B (resection and withdrawal of osteochondral's fragment in the medial condyle femoral and it is used as a autograft, after $180^{\circ}$ rotation, in anteroposterior sense and synthesis in contralateral's knee with monofilament suture wire absorbable polidioxanone - PDX) or technique C (resection and withdrawal of osteochondral's fragment in the medial condyle femoral, leaving the standard defect empty in contralateral's knees in those which they were operated by techniques A or B) as control. Results: They did clinical, radiographic, macroscopic and histological's studies in these 2 groups, showing the replacement of fragment or osteochondral's autograft, which facilities the perfect integration of fragment in the femoral condyle without shift or necrosis cartilaginous or osteal, in which knees were submitted by a simple resection of fragment, with following 42 days, there weren't cartilaginous formation in articular's surface having predispose to the osteophyte's formation, showing a significant relation between technique $\mathrm{C}$ and the presence of osteophytes. Conclusion: It comes to a conclusion that reconstitution of joint surface with replacement of fragment or osteochondral's graft fixed with suture wire PDX is feasible and it presented better result than a simple resection of the fragment.

KEY WORDS - Polidioxanone. Osteochondral fracture. Rabbit.

Conflito de interesse: nenhum Fonte de financiamento: nenhuma

Endereço para correspondência:

Celso Massaschi Inouye

Rua das Garças, 705

79010-020 Campo Grande - MS

Data do recebimento: $15 / 09 / 2002$

Data da revisão: 02/10/2002

Data da aprovação: 18/10/2002 